\title{
The structure of belief systems in the Dutch general public
}

\author{
HANSPETER KRIESI
}

\begin{abstract}
Several new concepts and measures for the analysis of political belief systems of citizens in liberal democracies are proposed. These concepts make a systematic distinction between values and beliefs about the status quo, and between the differentiation and integration of political belief systems. Applying the proposed instruments to the Dutch general public, the political beliefs of the average Dutch turn out to be fragmented, but not inconsistent. Traces of the two classic dimensions of ideological space could still be identified, as could indications of the existence of a third, 'new' dimension concerning political conflicts in 'new' issue areas. Moreover, even if the belief structures to be found are predominantly fragmented ones, taking them into account allows for more parsimonious explanations of important aspects of political attitudes and political behavior. The results are consistent with the present state of ideological flux in the Netherlands.
\end{abstract}

\section{INTRODUCTION}

At the end of the eighties, the end of ideology seems to have become reality after all. Thus, the Netherlands of the late eighties have been said to constitute an 'ideological vacuum' (Kalma, 1988: 19). Traditional ideological packages are disintegrating, and the three dominant political camps of the socialists, christian-democrats and liberals are all trying to reorient themselves. The declining saliency of traditional social cleavages, the challenge of the so-called new social movements in the cultural and ecological sphere, the growing unease with an ever-increasing welfare state, and the failure of classic macro-economic recipes have left all the traditional -isms in disarray. The end of the established ideologies does not, however, imply that general political ideas have become irrelevant for the political debate of the day (Stuurman, 1986). More accurately, the demise of the old ideologies seems to result in a state of ideological flux giving rise to a multiplication of partial world views falling short of the classic encompassing visions. As Dalton (1988) has shown in his analysis of the public opinion in the four major Western countries, political interests among the citizenry of Western democracies have in fact proliferated and diversified in the more recent past. In a similar vein, a number of researchers of Western European mass publics-Barnes and Kaase et al., (1979), Bürklin (1981), Dalton (1988) or Inglehart (1983) among others-have pointed to the emergence of a 'new politics' dimension involving conflicts over a new set of issues-environmental quality, alternative life styles, minority rights, participation, and social equality.

In this paper, I would like to study the extent to which the general political beliefs of the Dutch general public can be said to be structured at all under the present conditions of ideological flux. For this purpose I first introduce some conceptual distinctions with regard to the building blocks of belief systems. These distinctions build on an important tradition in American political science for which values are at the center of one's political beliefs. Following this tradition, I shall also assume that there are a limited number of basic dimensions structuring the ideological space, which are ultimately rooted in the societal cleavage structure. Under conditions of ideological flux, the number of these basic dimensions may increase, or they may lose their guiding capacity to a considerable 
extent. Nevertheless, according to the position taken here, the ideological space can still be expected to bear the mark of basic political conflicts of the past and the present.

\section{CONCEPTUALIZATION}

The building blocks of belief systems

Following the conception of values of Rokeach (1968: 124), an important tradition in American political science considers values to be a type of belief, centrally located within one's total belief system, about how one ought or ought not to behave, or about some end-state of existence worth or not worth attaining. Some of the major work on political belief systems, such as the one of Inglehart, essentially deals with values only. Although it contrasts with other classical conceptualizations in the social sciences (see Kluckhohn et al., 1951), I do not want to take issue with the inclusion of values in the general category of beliefs. I would like to suggest, however, that the nature of general belief systems could be clarified by a systematic distinction between values as 'conceptions of the desirable' and corresponding beliefs as 'conceptions of the real or possible'. According to the classical definition of Kluckhohn et al. (1951: 395), values are 'conceptions of the desirable' which provide general criteria for the selection among available means and ends in various specific situations. The cue words are 'right' or 'wrong', 'good' or 'bad'. Kluckhohn et al. deliberately included the word 'conception' in their definition. As they put it (p. 400), 'the combination of conception with desirable establishes the union of reason and feeling inherent in the word value'. 1 Political values in particular refer to general conceptions of the desirable type of society (van Deth, 1984: 65). For every political value, there is also a corresponding political belief about the existing state of society, and about the possibilities inherent in this society. This type of belief refers to the categories 'true' or 'false', 'correct' or 'incorrect'.

A given political value and the corresponding general political belief about the status quo may, but need not coincide. The conception of a given aspect of the desirable society may be in accord- ance with what one perceives as the reality of one's own society, or it may differ from one's conception of reality. If a given political value and the corresponding general political belief about the status quo are in agreement, the value serves to justify the existing reality. For example, someone who puts a high value on 'equality' and perceives the existing distribution of goods and privileges as equal, considers the status quo as just or good in this respect. The same applies to someone who values 'inequality' highly, and who perceives the real distribution of goods and privileges as unequal. For someone whose value does not agree with his or her perception of reality, the value is a justification for change, or, in Mannheim's terms, the value defines a utopia. ${ }^{2}$ There are conservative and progressive utopias. In the case of equality, a desired change in the direction of more equality would constitute a 'progressive utopia', while a desired change in the direction of less equality would constitute a 'conservative utopia'.

As Kluckhohn et al. (1951: 396) have put it, 'values are ideas formulating action commitments'. The direction and intensity of action commitments, however, can only be specified if the values are related to the corresponding beliefs about the status quo. We may assume that an individual actor who perceives a discrepancy between a given value and the corresponding general belief has a certain potential to take part in political action to change the existing situation, while an actor who does not perceive any discrepancy between the two is most likely not to have any potential for political action at all. In general, we can assume that the larger the discrepancy between a given political value and the corresponding belief, the greater will be the commitment to change in the desired direction.

Discrepancies between values and beliefs may develop as a result of a change of values and/or as a result of a change of corresponding beliefs about the real or possible. Studies of value change have tended to overlook this point, as is implicitly argued by Lowe and Rüdig (1986: 517f) in their critique of the research that attributes the rise of 'environmentalism' to a value change. ${ }^{3}$ Not only a change in the conception of the desirable, but also a change in the 
conception of the real, which is the result of real changes in the world we live in, may contribute to action commitments. Thus, the rise in 'environmentalism' may not necessarily result from a fundamental change of values, but from a changed perception of the real threat associated with the deterioration of environmental conditions. Instead of being a 'luxury' of those who have satisfied their basic needs and are, therefore, able to develop 'postmaterialist' values, 'environmentalism' may be a reaction to a change in basic beliefs, the result of an insight into the risks and limits involved in the evolution of modern societies (Kriesi, 1987).

If a perceived discrepancy between the desired state of society and the existing one may be assumed to be a necessary condition for commitment to political action, it is not a sufficient one. An actor may recognize a discrepancy between the desired and the real, but attach no great emotion to it. The value in question may have a relatively low priority within the actor's system of values. In this case, although the actor perceives a particular discrepancy between the desired social arrangement and the existing situation, s/he will evaluate this discrepancy as a comparatively minor one. Consequently, the actor's commitment to action implied by the discrepancy will turn out to be relatively low. It is the salience, centrality or intensity of a given discrepancy which is probably the most appropriate indicator of a commitment to action with regard to a given dimension of political values. It may be assumed that the salience of a given discrepancy increases with its size, i.e. the more a certain aspect of the desired state of society deviates from the existing one in someone's perception, the more salient it will be for the person in question.

This conceptualization of values and beliefs closely parallels Gurr's (1970) conceptualization of 'relative deprivation'. According to Gurr (1970: 23), the term 'relative deprivation' refers to 'the tension that develops from a discrepancy between the "ought" and the "is" of collective value satisfaction'. He defined 'relative deprivation' as the 'actors' perception of discrepancy between their value expectations and their value capabilities' (p. 24). An intensely felt discrepancy between a political value and the corre- sponding political belief about the existing state can be thought of as a particular instance of relative deprivation-a relative deprivation with regard to a general property of the type of society one would want to live in.

\section{The structure of belief systems}

Political values and corresponding general beliefs about the real or possible held by an individual citizen may form a more or less coherent whole. The concept of 'ideology' most closely corresponds to a coherent system of discrepancies between political values and general political beliefs about the status quo. Full fledged ideologies provide explicit, systematic maps of the existing world and of the world to be desired, they give a description of how the two relate to each other, and a prescription of how to get from the one to the other.

Ideologies can be thought of as hierarchical cognitive structures with different levels of abstraction. The more elaborate an ideology is, the more abstract the most abstract of its relatively central elements can be expected to be (Luskin, 1987). Moreover, elaborate ideologies imply a high degree of coherence of someone's political beliefs at an abstract level, and strong implications of the positions held at an abstract level for someone's more specific political beliefs. Recent studies have shown the utility of examining belief systems on at least two levels: general political beliefs, and issue-oriented beliefs (Sniderman et al., 1984; Peffley and Hurwitz, 1985). Accordingly, we can make a distinction between two types of constraints in political belief systems: 'horizontal' constraints, which refer to the structure of beliefs on each one of the two levels of abstraction, and 'vertical' constraints which refer to the correspondence between concrete beliefs and the more abstract or fundamental ones. In the subsequent analysis, I shall concentrate on the general political beliefs, and the question of 'horizontal' constraints among them.

Ideologies are considered to be collective cognitive maps rooted in fundamental societal conflicts and propagated by political organizations. The major ideologies have built on a few basic structural cleavages, which has tended to reduce the ideological space to a few underlying 
dimensions. In the American case, the ideological space has tended to be uni-dimensional, opposing liberals and conservatives. This simple one-dimensional model has recently been criticized by Conover and Feldman $(1981,1984)$, who suggest that there are multiple distinct schemas on different levels of abstraction in distinct subject areas which represent different ways of organizing political information. With respect to Western Europe, Lipset and Rokkan (1967) have suggested that there are two basic societal cleavages underlying the major ideologies: the cleavages of 'religion' and 'class'. Following their argument, the political ideologies that have patterned political beliefs over the past two centuries can be interpreted as the legacy of the political conflicts associated with these two basic cleavages. The main '-isms' have been shaped in the course of these two conflicts and, although transformed and adapted to changed circumstances, they can still be expected to build upon this legacy. Schematically speaking, the two conflicts have been about two fundamental political values: liberty and equality. ${ }^{4}$ On the class or social-economic dimension, a bourgeois position is opposed to a socialist one, on the religious or cultural dimension a liberal position faces a traditional one.

This two-dimensional conception has been criticized in two ways. First, an argument has been made that, in the course of the time, the two-dimensional structure described by Lipset and Rokkan has been reduced to a unidimensional contrast between the left and the right. For the Netherlands in particular, van der Eijck and Niemöller (1983: 224) have suggested that 'only a left-right dimension is of dominant and universal significance in people's political cognitions and preferences', since the economic and religious cleavages tend to be largely parallel. While accepting this type of reasoning, other scholars have discerned the more recent emergence of a new type of cleavage cutting across the traditional left-right one. As indicated previously, this alleged second cleavage is said to refer to new types of political issues which are not accommodated by the left-right dimension ${ }^{5}$. If we do not follow the reasoning of van der Eijck and Niemöller, and there are indications that their arguments are premature, ${ }^{6}$ the emergence of a new type of cleavage could even result in a three-dimensional ideological space.

The political beliefs of the mass public can be said to be coherently structured by collective ideologies to the extent that they are organized along a very limited number of underlying dimensions. In a state of ideological flux, we would expect this number to be increasing. Moreover, in such a situation even a pluridimensional space can be expected to fit the increasingly numerous combinations of individually held beliefs only to a limited extent. Quite generally, individuals are not 'passive bearers of ideology, but active appropriators' who interpret and apply ideological packages in the light of their proper experiences and resources (Willis, 1977: 175). But in a situation of ideological disarray, where they lack the guidance of dominant ideologies, idiosyncratic configurations of political beliefs can be expected to proliferate.

From the point of view of a given full-fledged collective ideology, idiosyncrasy may generally take one of two forms: inconsistency or fragmentation. Full-fledged ideologies are characterized by a high degree of differentiation and integration. A high degree of differentiation means that they include a large number of beliefs that cover the whole range of the political universe. By contrast, a high degree of integration means that the various beliefs included are tightly interconnected, or, in Converse's (1964) terms, constrained. Ideological inconsistency refers to a lack of integration. It implies that the various beliefs of an individual are not constrained by a given ideology, but that one subscribes to political beliefs belonging to different, or even conflicting ideological systems. Ideological fragmentation refers to a lack of differentiation. It implies that an individual only holds a limited number of beliefs which are restricted to a limited number of issue areas. In other words, inconsistency is indicative of a contradictory point of view, while fragmentation is indicative of a partial point of view. For example, people who, at one and the same time, defend some major tenets of socialist and bourgeois ideology are inconsistent, but those, who 
defend some major tenets of socialist ideology without caring about others, are partial.

Finally, it is important to distinguish inconsistency and fragmentation from indifference. An indifferent person does not have any political beliefs at all. Given the conceptualization of the building blocks of the individual system of political beliefs introduced above, a completely indifferent person does not perceive any discrepancies between the desired state of society and the existing one about which s/he feels strongly at all. ${ }^{7}$ While a state of ideological flux is likely to contribute to inconsistency and fragmentation, it does not seem to increase the amount of indifference (Dalton, 1988).

\section{OPERATIONALIZATION}

To operationalize these general conceptions, three types of questions were developed, to be asked for each one of 12 different political values and corresponding general beliefs about the real. The questions were presented-as part of a larger study-to a representative sample of 1,683 Dutch people aged 16 or older in 1987. The questions were asked by a computer assisted procedure (De Pijper and Saris, 1986), whereby the respondents answer the questionnaire in their own home. They are supplied with a home computer by the research organization. The interview is sent to the respondent by telephone as soon as $s /$ he switches on his or her computer, and the answers are also sent back to the research organization by telephone as soon as $\mathrm{s} / \mathrm{he}$ has concluded his or her interview.

The first question was concerned with a general political belief about existing Dutch society. The second question asked about the corresponding political value. ${ }^{8}$ Both of these questions had to be answered using a six-point scale. If the answers to the two questions did not agree, i.e. if a respondent saw a discrepancy between the existing situation and the desired type of society, s/he was confronted with the discrepancy and was asked to evaluate this discrepancy. S/he could do so by using the cursor of the computer to draw a line over a maximum of 38 columns. The longer the line the respondent drew, the stronger his or her feelings about the discrepancy in question. Figures A-1 to A-3 in the Appendix present the exact wording of the questions, using the example of the value aspect of 'law and order'.

Values are often operationalized by presenting respondents a list of items they are asked to rank. Such value instruments as the AllportVernon-Lindzey scale, the measures of Rokeach, or Inglehart's postmaterialism scale all make use of ranking procedures. Theoretical as well as methodological arguments are given for the choice of ranking procedures (van Deth, 1983: 410). Ranking is thought to be theoretically preferable, because it confronts the respondent with a situation of conflict where s/he, just as in real life, has to make a choice between a number of highly valued items. Ranking reveals individual priorities among items which are all supposed to be generally highly valued. Ranking is, therefore, also said to have the methodological advantage of introducing variation into the responses. If instead of ranking a separate rating of each value-item is asked for, and all the items are highly valued by almost everyone, analysis will be made virtually impossible because of lack of variation.

But ranking procedures also have serious shortcomings which, on balance, make me prefer ratings of separate items over rankings (van Deth, 1983). First of all, rankings imply that the measures of the different values are not independent of one another. As is well known, the statistical analysis of such interdependent, or 'ipsative', measures, is full of pitfalls. Secondly, rankings of items only have meaning for a given individual, and interpersonal comparisons of rankings should be distrusted: rankings inform us about the relative position of a given value in the individual value-system, but not about the measure of endorsement of a value on a scale common to all respondents. Take a respondent A who has to rank-order four values, all of which he finds very significant, and compare the ranking of this respondent to the one of a respondent $B$, who finds all the four values presented rather insignificant. The rank of a given value in the ordering of the two respondents does not tell us anything about the commitment to action involved. Third and most importantly from the point of view of the present study, the ranking procedure tends to 
imply an overestimation of structure at the individual level. It forces the respondent to compare a list of stimuli, which s/he has never thought about as being part of the same universe. The respondent may be induced to rankorder the stimuli, although they are, in part at least, incomparable to him or her.

To opt for ratings instead of rankings is not to eliminate the element of choice in the operationalization of values. Following Cotgrove and Duff $(1980,1981)$, I have presented the respondents for each value aspect with a choice between two types of ideal societies. They had to make a choice between the two, whereby they had the possibility of qualifying their preference on a six-points scale as is indicated in Figure A-2 in the Appendix. ${ }^{9}$ If all political values are consensual in a society, this procedure still implies a lack of variation for the analysis. But suppose that we find consensus with regard to a given value. As argued above, this does not yet imply that there are no differences in the population in terms of commitment to action con. cerning this value, since there may well be large differences with regard to the corresponding belief about the existing society in the population in question. To check the discriminatory capacity of different values and beliefs I have presented a small sample of respondents with 20 items in a pretest. The 20 items included in the pretest were selected pragmatically from among aspects which appeared to be crucial in the ideological packages of the major political forces, and in the public debate in the Netherlands at the time of the study. The choice of these 20 items was guided by the idea that the items should cover the whole range of beliefs associated by various authors with the cultural, socio-economic and the 'new' dimension of the ideological space. From these items I have picked the 12 that produced the largest overall discrepancies between values and corresponding beliefs for the study presented here. ${ }^{10}$

These 12 items cannot be unambiguously assigned to a distinct hypothetical underlying dimension on a priori grounds. Three of the selected items can be assumed to have a strong association with the cultural dimension-i.e. the items referring to 'law and order', 'church rules', and a 'strong army'. They all are concerned with the conflict between traditional authority and individual autonomy. But this is not their only reference point. Thus, the Christian element has been very strong in the (new) Dutch peace movement, and a pacifist element is also to be found in the socialist tradition. Four items refer to the hard core of the classic social-democratic program-'equality of opportunity', 'equality of income', 'full employment', and 'citizens' participation'. In other words, these items are supposed to correspond to the social-economic dimension. At the same time, however, 'equal opportunity' and 'participation' also play an important role in 'new' issue areas. The last five items, at first sight, seem to indicate various aspects of the 'new politics' dimension-two items referring to specific types of equality of opportunity (one for women, and one for foreigners), and one item each for 'environmental protection', 'new technologies', and 'meritocracy'. It is, however, possible that they do not all indicate the same 'new' dimension, or that they are also interrelated with more traditional aspects of the ideological space.

With regard to the wording of the items I have tried to account for the central, pervasive, and relatively enduring character of values while at the same time avoiding formulations so abstract as to be unintelligible for the general public. The idea was to tap the general conceptions that played a role in the issue-specific debates in the Netherlands at the time of the study, but not to ask about issue-specific attitudes. Figure 1 gives the exact wording of the 12 items I have finally chosen for the study, in the sequence as the items were presented to the respondents.

The subsequent analysis is based on the indicators for the intensity of a discrepancy between a given value and the corresponding belief about the status quo. As expected, the size of a given discrepancy is closely related to its salience. The correlations between discrepancies and corresponding intensities vary between 0.86 and 0.92 . These close correlations between discrepancies and intensities imply that higher intensities are attached to increasing discrepancies, irrespective of the sign of the discrepancy. That is, the emotions involved in conservative utopias are just as intensive as the ones involved in progressive ones. Although 
FIGURE 1 Exact wording of the 12 items used to operationalize values/beliefs

What do you find desirable? A society:/

How do you evaluate the existing Dutch situation? Is it a society:

1. with little/great emphasis on law and order

2. where people live independently of/according to church rules

3. with equal/unequal chances for all

4. with little/strong emphasis on equal chances for women

5. with participation/no participation of citizens in important government decisions

6. with rewards independent/dependent on achievements $(*)$

7. with no/strong differences in income

8. with equal chances for foreigners/better chances for Dutch

9. with no/great emphasis on full employment

10. where environment is more important than welfare/ welfare is more important than environment

11. where a very cautious use is made of new technologies/ where new technologies are strongly stimulated

12. with/without a strong army

Note: (a) this item will subsequently be called 'meritocratic orientation'

discrepancies and intensities are highly correlated, I prefer to rely on intensities, because, as I have argued above, intensities correspond more closely to the concept of 'ideas formulating action commitments'. I will subsequently use the signed intensities, the sign depending on the direction of the discrepancy. Respondents who, for whatever reason, are indifferent with regard to a given item are assigned an intensity of zero. The resulting intensity variables have a range from -38 to +38 .

\section{RESULTS}

\section{The structure of general beliefs}

To discover abstract ideological patterns, one has often looked at correlations. Table 1 presents the correlation matrix for the signed intensities for the whole sample. In this matrix, the 12 items are ordered into two clusters: the three aspects thought to be most strongly associated with the cultural dimension are listed first, followed by a cluster composed of the four items supposed to be related to the social-economic dimension, and of three of the five items supposed to indicate aspects of the 'new' dimension. The two items referring to meritocracy and new technologies are placed at the end of the Table. They hardly correlate at all with any of the other value aspects, and not with each other either. The two classic dimensions suggested by Lipset and Rokkan are visible to the extent that the intercorrelations between items belonging to the same cluster are, on the whole, somewhat higher than the intercorrelations between items not assumed to belong to the same cluster. But even the correlations within clusters are rather low. The overall impression is one of little integration of the ideological space, as we would have expected given the general situation of ideological flux.

Could we find a more coherent result, if we

TABLE 1 Correlation matrix for signed intensities (whole sample, $n=1683$ )

\begin{tabular}{|c|c|c|c|c|c|c|c|c|c|c|c|c|}
\hline Item & 1 & 2 & 3 & 4 & 5 & 6 & 7 & 8 & 9 & 10 & 11 & 12 \\
\hline 1. Law and order & - & & & & & & & & & & & \\
\hline 2. Church rules & 0.24 & - & & & & & & & & & & \\
\hline 3. Strong army & 0.24 & 0.24 & - & & & & & & & & & \\
\hline 4. Equal chances & -0.03 & $0 \cdot 18$ & 0.15 & - & & & & & & & & \\
\hline 5. Equal ch women & $0 \cdot 10$ & 0.25 & 0.17 & 0.33 & - & & & & & & & \\
\hline 6. Equal ch foreigners & $0 \cdot 12$ & $0 \cdot 17$ & $0 \cdot 18$ & 0.30 & 0.34 & - & & & & & & \\
\hline 7. Equal income & -0.03 & $0 \cdot 11$ & 0.20 & 0.46 & 0.26 & $0 \cdot 18$ & - & & & & & \\
\hline 8. Participation & -0.01 & $0 \cdot 20$ & $0 \cdot 18$ & 0.37 & 0.25 & 0.19 & 0.26 & - & & & & \\
\hline 9. Full employment & -0.16 & $0 \cdot 10$ & 0.07 & 0.27 & 0.15 & 0.08 & 0.26 & 0.25 & - & & & \\
\hline 10. Environment & -0.02 & $0 \cdot 15$ & $0 \cdot 15$ & 0.25 & $0 \cdot 19$ & 0.28 & $0 \cdot 12$ & 0.24 & 0.14 & - & & \\
\hline 11. Meritocracy & $0 \cdot 18$ & 0.09 & $0 \cdot 16$ & 0.07 & 0.09 & 0.12 & $0 \cdot 18$ & 0.01 & 0.01 & -0.03 & - & \\
\hline 12. New technology & 0.04 & -0.04 & $0 \cdot 10$ & 0.08 & 0.04 & 0.04 & 0.23 & 0.03 & 0.02 & $0 \cdot 01$ & $0 \cdot 10$ & - \\
\hline
\end{tabular}


TABLE 2 Correlations among indicators of general beliefs: averages for the 12 items, and standard deviations(n)

\begin{tabular}{lccccc}
\hline & & & \multicolumn{2}{c}{$\begin{array}{c}\text { Those most } \\
\text { concerned }\end{array}$} \\
Type of belief & Average r & S.D. & Average r & S.D. \\
\hline Beliefs about & & & & \\
$\quad$ status quo & 0.08 & 0.09 & 0.12 & 0.11 \\
Values & 0.10 & 0.10 & 0.15 & 0.13 \\
Discrepancies & 0.14 & 0.11 & 0.20 & 0.14 \\
Signed intensities & 0.15 & 0.11 & 0.20 & 0.13 \\
\hline
\end{tabular}

Note: (a) Respondents who don't know or do not want to give an answer are coded in a neutral position.

were to base our analysis on a different building block, i.e. on values, beliefs, or signed discrepancies instead of on signed intensities? Table 2 presents the average correlations between beliefs about the status quo, values, signed discrepancies, and signed intensities for the whole sample, and for a group of persons who are particularly concerned with questions of political beliefs. ${ }^{11}$ As this Table shows, we could not have done better by choosing a different unit of analysis. Quite to the contrary, while the differences with the signed discrepancies are slight, the signed intensities are more strongly patterned than beliefs about the status quo or values. This indicates that we gain some information about ideological structures by systematically relating values and beliefs about the status quo. As expected, the average correlations turn out to be somewhat higher for those who are particularly concerned with general beliefs. However, even for this select group the emerging pattern is a rather loose one. This can be taken as a strong indicator of the presumed situation of general ideological disintegration.

Luskin (1987: 869) maintains that correlations tell us little about political sophistication. According to his view, even sizeable correlations are not necessarily good indicators of sophistication. Large correlations, he argues, only mean that the respondents' answers are internally consistent, but not that they have consciously thought about the items involved. The consistency may result entirely from cue taking, or from unreflected common experiences. If any- thing, he concludes, correlations between attitudes do not tend to be 'too low', but 'too high'. However, taken as indicators of ideological patterning of individual thinking-whatever its origin-correlations are neither 'too low', nor 'too high'. ${ }^{12}$ The low correlations we find are likely to reflect quite accurately the fact that under conditions of disintegration of classical ideologies, external cue taking hardly contributes to coherent views at all.

The question is whether under these conditions we can find any structure in the political beliefs of the Dutch public at all. In order to answer this question, I have made use of latent attitude models. Latent attitude models assume that most respondents have real preferences that remain stable over time. If the structure of these preferences does not become visible in the correlation matrix, these models assume that this is because of measurement errors. As Inglehart (1985) points out, measurement errors indicate random answering which is the result of the pervasive phenomenon of lack of time and motivation in the survey situation. ${ }^{13}$ To test whether there is an underlying preference structure which may be masked by measurement errors, I have analyzed the correlations between the signed intensities with LISREL VI. From this analysis I have excluded the two items which are hardly connected to the other ten items at all. I have performed separate analyses for the whole sample, and for the group of those most concerned. In a stepwise fashion, I have tested different models with varying numbers of underlying dimensions. Table 3 presents the CHISQGoodness of fit measures for the different models as well as their degree of freedom.

Whether we take the sample as a whole, or only the group of those most concerned, the Table shows that none of the models fits the data very well. However, the general message of this series of tests is quite clear: the fit of the model can be significantly improved by combining the introduction of additional underlying dimensions with certain modifications of the original specification. The baseline model is a 1-factor model representing a hypothetical left-right dimension. The 2-factor model $A$ is thought to operationalize Lipset and Rokkan's classic twodimensional ideological space, the two dimen- 
TABLE 3 Tests for dimensionality of ideological space: alternative factor models for whole sample and group most concerned

\begin{tabular}{lcccc}
\hline & \multicolumn{2}{c}{$\begin{array}{c}\text { Whole sample } \\
(\mathrm{n}=1683)\end{array}$} & \multicolumn{2}{c}{$\begin{array}{c}\text { Those most concerned } \\
(\mathrm{n}=340)\end{array}$} \\
Model & CHSQ & d.f. & CHISQ & d.f. \\
\hline 1. 1-factor-model & $436 \cdot 45$ & 35 & $180 \cdot 91$ & 35 \\
2. 2-factors A, uncorr. & $446 \cdot 16$ & 35 & $200 \cdot 28$ & 35 \\
3. 2-factors A, corr. & $330 \cdot 00$ & 34 & $130 \cdot 92$ & 34 \\
4. 2-factors B, uncorr & $879 \cdot 84$ & 35 & $321 \cdot 47$ & 35 \\
5. 2-factors B, corr. & 428.91 & 34 & $176 \cdot 23$ & 34 \\
6. 2-factors C, uncorr. & 247.79 & 33 & 127.67 & 33 \\
7. 3-factors, uncorr. & $333 \cdot 30$ & 31 & $128 \cdot 15$ & 31 \\
8. 3-factors, + PH(3,2) & $199 \cdot 84$ & 30 & 81.66 & 30 \\
9. 3-factors, + PH(3,1), PH(3,2) & $139 \cdot 42$ & 29 & $64 \cdot 63$ & 29 \\
\hline
\end{tabular}

sions being assumed to be independent of each other. In this model, the three 'cultural' items have been assigned to the first dimension. The remaining seven items have all been used as indicators of the social-economic dimension, assuming that the 'new' dimension is not to be distinguished from the social-economic one. A comparison of the fit of this model with the baseline model indicates that this model represents a significant improvement, but only if we allow the two factors to be correlated. The correlations between the two factors turn out to be quite substantial $(r=0.51$ and 0.62 for the whole sample, and for those most concerned respectively).

The 2-factor model B corresponds to the combination of a left-right dimension with a 'new' one. In this case, the three 'cultural' items, 'equality of opportunity', 'equality of income', and 'full employment' have been used as indicators of the left-right continuum, while the remaining four items-'participation', equality of opportunity for 'women' and for 'foreigners', and 'environmental protection'-have been assigned as indicators for the 'new' dimension. As can be seen from Table 3, such a model does not fit the data at all, if we do not allow the two factors to correlate. Moreover, even if we allow for correlated factors, it does not represent any improvement over the baseline model. This is not surprising, because the two factors turn out to be very strongly correlated $(r=0.91$ and 0.90 respectively). In other words, the idea of a second 'new' issue-cleavage cross-cutting the classic left-right dimension does not seem to be very promising for the case of the Netherlands.

The 2-factor model can, however, be substantially improved by allowing two of the three indicators of the cultural dimension-the items for 'church rules' and for 'strong army'-to be indicators of the social-economic dimension as well (2-factor model C). Substantively, this implies that the two indicators do not exclusively tap the underlying distinction between traditional authority and individual liberty, but that they have other aspects as well. With regard to the churches in the Netherlands, it may plausibly be argued, as already indicated, that they have long been concerned with issues dealing with social justice and peace. With regard to the army, it may also be argued quite plausibly that it has divided socialists from partisans of a bourgeois point of view, independently of questions relating to traditional authority and individual liberty.

The 3-factor model drops the assumption that the 'new' dimension has been completely assimilated by the social-economic one. It posits a third factor for the 'new' politics. The indicators for the 'new' politics are supposed to be: all items for equality of opportunity, environmental protection, participation, and the item concerning the churches (given the strong support the peace movement has found in the churches). 
TABLE 4 Factor loadings and reliabilities for the best three-factor model

\begin{tabular}{lcccc}
\hline Item & $\begin{array}{c}\text { Factor 1 } \\
\text { (cultural) }\end{array}$ & $\begin{array}{c}\text { Factor 2 } \\
\text { (social- } \\
\text { economic) }\end{array}$ & $\begin{array}{c}\text { Factor 3 } \\
\text { ('new') }\end{array}$ & Reliability \\
\hline 1. Law and order & 0.593 & - & - & 0.351 \\
2. Church rules & 0.322 & - & 0.318 & 0.261 \\
3. Strong army & 0.461 & 0.293 & - & 0.288 \\
4. Equal opportunity & - & 0.579 & 0.200 & 0.520 \\
5. Equal income & - & 0.625 & - & 0.391 \\
6. Full employment & - & 0.426 & - & 0.181 \\
7. Participation & - & 0.226 & 0.323 & 0.247 \\
8. Equal opp. women & - & - & 0.591 & 0.345 \\
9. Equal opp. foreigners & - & - & 0.539 & 0.286 \\
10. Environment & - & - & 0.388 & 0.148 \\
\hline
\end{tabular}

The indicators for the social-economic dimension, i.e. essentially for classic social-democratic politics, as opposed to bourgeois politics, are: equality of opportunity for all (but not for foreigners or women in particular), equality of incomes, full employment, participation, and the item concerning the army (given the division between social democrats and bourgeois parties with regard to the army). As is indicated by Table 3 , the introduction of a third factor only improves the fit of the model, if we allow it to be correlated with the first two. In that case, however, the improvement is substantial, which suggests that the underlying ideological space has at least three dimensions. While the first two dimensions in this model are independent of each other, the third dimension turns out to be moderately correlated with the cultural one $(r=0 \cdot 31)$, and substantially with the socialeconomic one $(r=0.64)$. This indicates that the content of the 'new' dimension is related to the one of the classical two, but that there is still reason to take into account its separate existence. ${ }^{14}$

Table 4 presents the factor-loadings for the final 3-factor model for the whole sample, as well as the reliabilities of the different indicators. All loadings are significant, even if they are not all very impressive. The reliabilities are quite low, too, as we could have expected. For the group of those most concerned we essentially obtain the same results, with somewhat higher reliabilities. This is to say that even a three-dimensional solution does not represent the ideological space very well. Although I have excluded the two apparently unrelated 'new' aspects from the analysis, the resulting structure cannot be called anything but loose.

\section{Inconsistency or Fragmentation?}

Is this lack of structure an expression of inconsistent or of partial views on the part of the individual citizens? To find an answer to this question, I have first followed a suggestion of Barton and Parsons (1977): I have calculated the standard deviation of an individual's responses to the different items associated with a given factor from his or her own mean. This measure tells us whether an individual tends to answer all the items which are supposed to indicate the same underlying dimension in the same substantive direction, or whether s/he is inconsistent across items. Applying this measure to the Dutch data, I have found a rather unexpected result: the more a person is interested in politics, and the more someone is concerned about general political beliefs, the larger the size of one's standard deviation, i.e. the more inconsistent the person appears to be according to the measure of Barton and Parsons.

How is this possible? The problem of the measure proposed by Barton and Parsons is that 
TABLE 5 Fragmentation and inconsistency of the belief systems of the Dutch general public: percentages having strongly felt discrepancies, social-economic dimension, 2-factor model $A^{(*)}$

\begin{tabular}{|c|c|c|c|c|c|c|c|c|}
\hline \multirow{2}{*}{$\begin{array}{l}\text { Number of } \\
\text { strongly felt discrepancy } \\
\text { bougeois direction }\end{array}$} & \multicolumn{8}{|c|}{ Number of strongly felt discrepancy in socialist direction } \\
\hline & 0 & 1 & 2 & 3 & 4 & 5 & 6 & 7 \\
\hline 0 & 13.8 & 11.6 & $11 \cdot 3$ & $12 \cdot 1$ & $11 \cdot 1$ & $9 \cdot 2$ & 6.9 & 3.5 \\
\hline 1 & $2 \cdot 3$ & $2 \cdot 5$ & $2 \cdot 8$ & 3.6 & $2 \cdot 4$ & $1 \cdot 3$ & $1 \cdot 2$ & - \\
\hline 2 & 0.3 & 1.0 & 0.7 & 0.5 & 0.4 & $0 \cdot 2$ & - & - \\
\hline 3 & $0 \cdot 1$ & 0.4 & 0.3 & - & - & - & - & - \\
\hline 4 & 0.1 & - & - & 0.1 & - & - & - & - \\
\hline 5 & - & 0.2 & 0.1 & - & - & - & - & - \\
\hline
\end{tabular}

Note: (a) strongly felt discrepancies are being defined as discrepancies felt with an intensity of at least +20 .

it is not a pure measure of inconsistency. It is also a function of the degree of fragmentation of an individual's belief system. Someone with a partial view, i.e. with strong feelings about selected items only, will also be characterized by a high standard deviation. Moreover, according to this measure an indifferent person turns out to be highly consistent. Indifferent citizens do not have any strong feelings about politics at all and, therefore, their attitudes show no great variation across the different aspects of the belief system. ${ }^{15}$ This paradoxical result can be explained by the fact that people who are interested in politics and who are concerned about general political beliefs are more likely to hold some strong views about basic political beliefs than the average citizen, but that their views, too, tend to be partial ones.

The views of the Dutch general public are not so much inconsistent but partial: only 10 per cent of the sample have discrepancies on all dimensions, and only very few people ( 0.4 per cent) have strongly felt discrepancies (intensities of +20 ) on all dimensions. The relative importance of fragmentation and inconsistency becomes apparent, if we consider the distribution of strongly felt discrepancies with regard to a single factor in detail. Table 5 shows this distribution for the example of the socialeconomic dimension of the 2-factor model A. For each respondent, the number of strongly felt discrepancies have been counted separately for the socialist direction and the bourgeois direction. Since there are seven items associated with this factor, the maximum number of discrepancies in a given direction is seven. As can be seen from the cross tabulation in Table 5 , the majority of the respondents feel strongly about only a few items, and all their strong feelings tend to point in the same direction. With regard to this cluster of items, roughly two-thirds of the sample (68.5 per cent) have strongly felt discrepancies in one direction only, about one-seventh (13.8 per cent) does not have any strongly felt views at all, and only 17.7 per cent have at least somewhat inconsistent views. Similar results can be obtained for all the dimensions in the different models. We may, thus, conclude that it is not so much inconsistency, but fragmentation of world views which is responsible for the overall lack of structure in the belief systems of the Dutch.

This result confirms Dalton's (1988) idea of a diversification of political interests. As he put it (p. 28): 'Everybody is sophisticated, only on different subjects.' Given the complexity of political life, its unintelligibility in a situation of ideological disarray, ordinary citizens economize time and energy by focusing on selected aspects of the political universe particularly salient to them. Of course, this sort of partial sophistication falls short of the ideal of differentiated and integrated belief systems, but it is an indication of sophistication nevertheless. As is also indicated by Table 5 , the differentiation and integration of belief systems is a matter of degree. While only very few people have a fully differentiated and integrated belief 
system, a much larger share of the citizens hold political views which approach the ideal to a considerable extent.

To arrive at overall measures of the degree of differentiation and integration of individual belief systems, I propose to construct summary scales. These scales should take into account the dimensionality of the ideological space. That is we need separate measures for the different dimensions. These measures should also take into account the fact that most views are partial ones, i.e. minor and selective discrepancies should contribute to the size of the scales just as well as substantial and encompassing ones. Finally the scales should take care of apparent inconsistencies. In other words, their size should be proportional to the number, and to the intensity of discrepancies associated with a given dimension, which point in the same direction. Discrepancies of different signs associated with the same dimension should, however, reduce its size. The mean value of an individual's signed intensities with respect to all the items associated with a specific dimension fulfills all of these exigencies. More sophisticated but essentially similar measures are provided by an individual's factor score on a given dimension of the ideological space: factor scores are nothing else but weighted means of the standardized signed intensities associated with a given dimension. ${ }^{16}$

The relevance of the structure of belief systems Finally, let me briefly approach the question of the relevance of the structure of general political beliefs for the analysis of political attitudes and political behaviour. I have tried to predict two important indicators which are likely to be determined by general political beliefs-selfplacement on the left-right scale, and support for new social movements ${ }^{17}$ - on the basis of the summary scales associated with the 1-factor model, and with the best 2-factor and 3-factor models. The predicative capacity of these three models is compared to the one of the original set of the 12 signed intensity items, to the one of the two best predictors among the original items, and to the one of Inglehart's postmaterialism scale. Table 6 presents the results. Comparing first the three models among themselves, we note that the 3-factor model does better than the
TABLE $6 \quad R^{2}$ 's for different predictors of left-right selfplacement and of support for new social movements

\begin{tabular}{lcc}
\hline & $\begin{array}{c}\text { Left-right } \\
\text { self- } \\
\text { placement }\end{array}$ & $\begin{array}{c}\text { Support for } \\
\text { NSMs }\end{array}$ \\
\hline 1. 1-factor model & 0.30 & 0.36 \\
2. 2-factor model C & 0.32 & 0.38 \\
3. 3-factor model & 0.33 & 0.40 \\
4. 12 original items & 0.34 & 0.41 \\
5. 2 best original items & 0.23 & 0.21 \\
6. postmaterialism scale & 0.11 & 0.14 \\
\hline
\end{tabular}

other two. However, the differences in performance between the three are quite small. Given the limited advantage in predictive power of the more complex models, one might want to prefer the 1 -factor model for reasons of parsimony. However, this model has been shown to fit poorly the overall structure of the Dutch belief system. This means that we lose important information, if we use the 1-factor model, information which is contained in the 3-factor model, which fits the structure rather well.

This information is conveyed by Table 7 . Left-right self-placement turns out to be strongly influenced by one's position on the first two, classical dimensions, but it is unrelated to one's position on the third, 'new' dimension. This is a very important result in the light of the discussion on the dimensionality of the ideological space and on the meaning of the left-right continuum in Western European politics. Cultural liberalism as well as social-

TABLE 7 Left-right self-placement, support for NSMs, and ideological position: BETA-coefficients and $R^{2}$-adjusted(*)

\begin{tabular}{lcc}
\hline & $\begin{array}{c}\text { Left-right } \\
\text { self- } \\
\text { placement }\end{array}$ & $\begin{array}{c}\text { Support for } \\
\text { NSMs }\end{array}$ \\
\hline 1. Cultural dimension & $-0.36^{* * *}$ & $0.22^{* * *}$ \\
2. Social-economic dim. & $-0.42^{* * *}$ & $\begin{array}{l}0.11^{* *} \\
0.41^{* * *}\end{array}$ \\
3. 'New' dimension & $n s$. & 0.40 \\
\hline$R^{2}$-adjusted & 0.33 & 0.40
\end{tabular}

Note: (a) ns = not significant, ${ }^{*}$ significant at the 1 per cent level, *** significant at the $0 \cdot 1$ per cent level.

(b) scale ranging from 1 (left) to 10 (right). 
democratic views on the social-economic dimension both contribute to left self-placement. On the other hand, one's position on the 'new' dimension is the best predictor of support for the so-called 'new' social movements. Support for these movements is also enhanced to some extent by cultural liberalism, and, less significantly, by social-democratic views on socialeconomic matters. Without going into the details, this result is in line with the notion that the disintegration of the classic ideological space is-among other things-linked to the mobilization of the new social movements.

Comparing the predictive power of the 3 factor model to the one of the original 12 items, we virtually find no difference at all. This means that one could not do better by taking into account all the details of the belief system. Or, in other words, the uncovering of the essential elements of structure allows for a considerable amount of parsimony in our explanation. Moreover, to neglect considerations about structure and to try to be parsimonious on purely inductive grounds would mean to lose a considerable amount of predictive power. This is indicated by the performance of the two best predictors among the original items-'strong army' and 'equal income'. Inglehart's postmaterialism scale,$^{18}$ finally, provides an external benchmark for the evaluation of the performance of the scales constructed here. As Table 6 shows, the predictive performance of this widely used scale for political beliefs falls far short of any of the measures elaborated here.

\section{CONCLUSION}

I have proposed some concepts and measures to analyze the structure of general political belief systems of citizens in liberal democracies which build on existing approaches that concentrate on the analysis of political values. Applying these concepts and measures to the belief systems of the Dutch general public, I have found that these are rather loosely structured, as was to be expected given the present state of ideological flux. Traces of the two classic dimensions of ideological space could nevertheless still be identified, as could indications of the existence of a third, 'new' dimension concerning political conflicts in 'new' issue areas. Conceptualizations of the ideological space which assume that the classical two dimensions can be collapsed into a single, left-right continuum did not turn out to be appropriate representations of the Dutch situation. The relative absence of well integrated, encompassing belief systems does, however, not imply that citizens generally hold inconsistent beliefs. Under the conditions of ideological flux, citizens do not so much hold inconsistent, but partial views. But even if the belief structures we found are predominantly partial ones, it is well worth to take them into account. Doing so allows for more parsimonious explanations of important aspects of political attitudes and political behavior.

The results obtained obviously reflect the specificities of the Dutch context in the late eighties. The degree of ideological flux may vary from one country to the other, and between different periods in one and the same country. Such variation will considerably affect the number and kind of dimensions of the ideological space, as well as the extent of horizontal and vertical constraint to be found. The concepts and measures proposed are, however, not tied to a given political context. They could be applied to other contexts in an analogous fashion to permit systematic comparisons across time and space.

\section{NOTES}

1. It is important to note that this approach to values contrasts with the basic assumptions of Inglehart's (1977) very influential conceptualization. While Inglehart's theory is essentially psychological and derives value-orientations from the perspective of a Maslovian hierarchy of needs, the conceptualization of Kluckhohn's $e t$ al. is essentially sociological and starts from the idea that needs are interpreted within a conceptual framework that already includes strong value components. As these authors point out (p. 428): 'Values both rise from and create needs. A value serves several needs partially, inhibits others partially, half meets and half blocks still others.' In the same vein, Cotgrove (1982: 50f) maintains that the generation and distribution of values cannot be explained simply in terms of need satisfaction or deprivation. Material needs, he suggests, are met within the context of specific social arrangements. Values refer as much to the "pull of aspirations and ideals' as they do to the 'push of needs'.

2. I refer here to Mannheim's distinction between 'ideologies' and 'utopias': while 'ideologies' in 
Mannheim's terminology consist of beliefs which justify existing social arrangements, 'utopias' justify change. I shall give a different interpretation to the concept of 'ideology' below.

3. One of the main reservations they have about such an interpretation is 'that this effectively divorces environmental concern from ecological problems. The environment is seen as just one among many "post-materialist" issues which suddenly emerged to prominence, unrelated to any change in the environment, through a shift in values among people who had nothing else to worry about.'

4. Rokeach (1973) also distinguishes between these two fundamental dimensions of values, although he does not talk about 'political values' but about 'political ideologies'.

5. The new cleavage behind this alleged second dimension is no longer seen to be rooted in social structure, but is assumed to exist only on the basis of 'issue groups' (see, e.g. Dalton, 1988: 175). Needless to say that this implies a rather unorthodox interpretation of the concept of 'cleavage'.

6. It can, for example, be shown that the depillarization of Dutch society did not render the religious cleavage irrelevant. By increasing the number of those who no longer belong to a church, and by weakening the intensity of the affiliation of those who still belong, the more general process of secularization has rendered religion less relevant for the orientation of an increasing part of the Dutch voters. For those who remain strongly affiliated with a church, however, voting behavior is still largely determined by their religious orientation (see van der Eijck and Niemoller, 1983a; Thomassen, 1983).

7. One might object that someone who does not feel strongly about any such discrepancies may be a highly self-conscious defendant of the status quo. While being aware of this possibility, I still think that it is very unlikely that a politically sophisticated person takes such an extremely uncritical point of view of the status quo.

8. To check whether the sequence of the first two questions affects the answers given, I ran a pretest with a split sample of 69 respondents, half of which received the value question first, followed by the belief question. The other half received the questions in the sequence given here. The mean responses of the two groups with regard to values and beliefs were then tested for significant differences. Of the 40 t-tests performed-20 items for values and beliefs each-, only three turned out to be significant. This I took as an indication that the sequence of the two questions did not affect the answers given.

9. Following the advice of Converse and Presser (1986), no middle position was allowed for, but I added a category for 'don't know/no opinion'. In the pretest, I used a seven-point scale without a 'don't know/no opinion' category. In combination with the fact that in the pretest, the cursor was preset on the middle category for this question and had to be moved along the horizontally placed seven-points scale in order to answer the question, this induced an unexpectedly large number of respondents to choose for the middle position.

10. The items dropped because of lack of variation included: influence of experts, welfare services, economic growth, possibilities for alternative lifestyles, government control over the citizens' privacy, participation in decision making on the job, government control over business, support for scientific progress.

11. After the questions about the belief systems, the respondents have been asked how often they think about these matters. One-fifth of the respondents indicated that they 'often' think about such fundamental political questions. They represent the group of those who are most concerned by these matters.

12. With regard to individual political sophistication, Luskin's point is, of course, well taken. Correspondence between an individual's belief system and a collective ideology may be the result of a rather rigid adherence to a party-line, while an idiosyncratic configuration of political beliefs could be the mark of an individual with a truly well-developed belief system (Barton and Parsons, 1977: 178).

13. An intriguing question is whether measurement errors may also indicate a lack of consistency on the part of the respondents, as Converse (1980) suggests in his rejoinder to Judd and Milburn (1980).

14. For the group most concerned, the correlation with the cultural dimension is almost the same as for the sample as a whole $(r=0 \cdot 34)$, while the one with the socialeconomic dimension is somewhat smaller $(r=0.48)$.

15. Hamill et al. (1985: 856) try to take into account this problem by introducing a weighting procedure, which is, however, not made very explicit in their article.

16. The essential similarity of the simple means, and of the factor scores is illustrated by the fact that the factor scores for the best two-dimensional solution (model C) and the corresponding simple means correlate with 0.97 for the social-economic dimension, and with 0.92 for the cultural dimension. For the three-dimensional solution (final model), the correlations for the three dimensions are: $0.96,0.98$, and 0.91 . Apparently, the weights employed by the factor scores do not have a substantial impact on the final summary measures.

17. Self-placement on a left-right scale has been measured in a straightforward way on a ten-point scale. The measure for the support of new social movements is based on questions asking about sympathy, readiness for participation, and participation in five different such movements - the ecology, anti-nuclear, women's, peace, and anti-apartheid movement. Indicators for the support of each of these movements, and a summary indicator for the support of all of them have been constructed.

18. For this comparison, I have used the postmaterialism index based on Inglehart's original four-item procedure. As has been shown by Hagstotz (1985), this simple procedure leads to a scale which is in agreement with the theoretical assumptions made by Inglehart. The ordinal scale based on this procedure has four categories: (1) materialist; (2) rather materialist; (3) rather postmaterialist; (4) postmaterialist. 


\section{REFERENCES}

Barnes S H, Kaase M et al. (eds) (1979): Political Action. Mass Participation in Five Western Democracies, London: Sage.

Barton A H, Parsons' W R. (1977): 'Measuring Belief System Structure', Political Opinion Quarterly, 41: $159-80$.

Bürklin W P. (1981): 'Die Grünen und die "Neue Politik”', Politische Vierteljahresschrift, 21: 359-82.

Conover P Johnston and Feldman S. (1981): 'The Origins and Meaning of Liberal/Conservative Self-Identification', American Journal of Political Science, 25: $617-45$.

- (1984): 'How People Organize the Political World: A Schematic Model', American Journal of Political Science, 28: $95-126$.

Converse P E. (1964): 'The nature of belief systems in mass publics', pp. 201-61, in Apter D E, (ed), Ideology and Discontent, New York: Free Press.

- (1980): 'Rejoinder to Judd and Milburn', American Sociological Review, 45: 644-46.

Converse J M, Presser S. (1986): Survey Questions. Handcrafting the Standard Questionnaire, London: Sage.

Cotgrove S. (1982): Catastrophy or Cormucopia. The Environment, Politics and the Future, Chichester: Wiley.

Cotgrove S, Duff A. (1980): 'Environmentalism, middleclass radicalism and politics', Sociological Review, 28: 333-51.

- (1981): 'Environmentalism, values, and social-change', British Journal of Sociology, 32: 92-110.

Dalton R J. (1988): Citizen Politics in Western Democracies, Chatham, NJ: Chatham House.

Deth J W van. (1983): 'Ranking the ratings: the case of materialist and postmaterialist value orientations', Political Methodology, 9: 407-32.

- (1984): Poltieke Waarden. Een onderzoek naar politieke waarde-orientaties in Nederland in de periode 1970 tot en met 1982, Amsterdam: CT-Press.

Eijck C van der, Niembller B. (1983): Electoral Change in the Netherlands. Empirical results and methods of measurement, Amsterdam: CT-Press.

- (1983a): 'Stemmen op godsdienstige partijen sinds 1967', Acta Politica, 18: 169-82.

Gurr T R. (1970): Why Men Rebel, Princeton University Press.

Hagstotz W. (1985): 'Welcher Inglehart-Index ist der richtige? Methodische Anmerkungen zur Messung von Wertorientierungen', ZUMA-Nachrichten, 16: 15-38.

Hamill R, Lodge M, Blake F. (1985): 'The Breadth, Depth, and Utility of Class, Partisan, and Ideological Schemata', American Journal of Political Science, 29: 850-70.

Inglehart R. (1977): The Silent Revolution. Changing Values and Political Styles among Western Publics, Princeton University Press.

_- (1983): "Traditionelle politische Trennungslinien und die Entwicklung der neuen Politik in westlichen Gesellschaften', Politische Vierteljahresschrift, 24: 139-56.
Inglehart R. (1985): 'Aggregate Stability and IndividualLevel Flux in Mass Belief-Systems: The Level of Analysis Paradox', American Political Science Review, 79: $97-116$

Judd Ch M, Milburn M A. (1980): 'The Structure of Attitude Systems in the General Public: Comparisons of a Structural Equation Model', American Sociological Review, 45: 627-43.

Kalma P. (1988): Het socialsme op sterk water. Veertien stellingen, Deventer: Van Loghum Slaterus.

Kluckhohn C et al. 1951 (1962): 'Values and valueorientations in the theory of action. An exploration in definition and classification', pp. 388-433, in Parsons T, Shils E A, (eds), Towards a General Theory of Action, New York: Harper and Row.

Kriesi H. (1987): 'Neue soziale Bewegungen: Auf der Suche nach ihrem gemeinsamen Nenner', Politische Vierteljahresschrift, 28: 315-34.

Lipset S M, Rokkan S. (1967): 'Cleavage structures, party systems and voter alignments: an introduction', pp. 1-67, in Lipset/Rokkan, (eds), Party Systems and Voter Alignments: Cross-national Perspectives, New York: Free Press.

Lowe P D, Rudig W. (1986): 'Review article: political ecology and the social sciences-the state of the art', British Journal of Political Science, 16: 513-50.

Luskin R C (1987): 'Measuring Political Sophistication', American Journal of Political Science, 31:856-99.

Peffley M A, Hurwitz J. (1985): 'A Hierarchical Model of Attitude Constraint', American Journal of Political Science, 29: 871-90.

Pijper W M de, Saris W E. (1986): The formulation of interviews using the program interv. Amsterdam: Sociometric Research Foundation.

Rokeach M. (1973): The Nature of Human Values, New York: Free Press.

- (1968): Beliefs, Attitudes and Values, San Francisco: Jossey-Bass.

Sniderman P M, Brody R A, Kuklinski J H. (1984): 'Policy Reasoning and Political Values: The Problem of Racial Equality', American Journal of Political Science, 28: 75-94.

Stuurman S. (1986): Moderniteit en politieke theorie, Nijmegen: SUN.

Thomassen J J A. (1983): 'Veranderingen in partijorientaties', pp. 108-40, in Thomassen J J A et al. (eds), De verstomde revolutie, Alphen aan den Rijn: Samsom.

Willis P. (1977): Learning to labour. How working class kids get working class jobs, Aldershot: Gower.

\section{AUTHOR'S ADDRESS}

Prof. Hanspeter Kriesi, Université de Genève, Faculté des Sciences Economiques et Sociales, 7, Route de Drize, Case Postale 266, CH-1227 Carouge-Genève, Switzerland.

Manuscript received: February 1990. 


\section{APPENDIX}

FIGURE A-1 Exact wording of the question about existing Dutch society (political belief)

Do you think that in Dutch society one puts RELATIVELY LITTLE EMPHASIS on LAW AND ORDER, or do you think that in the Netherlands one puts a RELATIVELY GREAT EMPHASIS ON LAW AND ORDER.

If you think that in the Netherlands one puts LITTLE emphasis on law and order, type 1 or a number close to 1 .

If you think that in the Netherlands one puts GREAT emphasis on law and order, type 6 or a number close to 6 .

Is the existing society one with

1. LITTLE EMPHASIS ON LAW AND ORDER

2.

3.

4.

5.

6. GREAT EMPHASIS ON LAW AND ORDER

7. Don't know/no opinion

FIGURE A-2 Exact wording of the question about the desirable Dutch society (political value)

And now the question about what, according to your opinion, is DESIRABLE in the Netherlands.

What do you find DESIRABLE?

1. LITTLE EMPHASIS ON LAW AND ORDER

2.

3.

4.

5.

6. GREAT EMPHASIS ON LAW AND ORDER

7. Don't know/no opinion
FIGURE A-3 Exact wording of the question about the evaluation of the discrepancy between the political value and the corresponding belief

You indicated that the existing situation and the one you desire differ from each other.

We now want to know HOW SERIOUS you think this discrepancy is.

We show you once again your answers:

you gave the EXISTING situation (value from question 1)

and the DESIRABLE situation (value from question 2)

$1=$ LITTLE EMPHASIS ON LAW AND ORDER

6=GREAT EMPHASIS ON LAW AND ORDER

If you find this discrepancy VERY SERIOUS, draw this line:

If you find the discrepancy NOT SERIOUS AT ALL, draw this line:

$-$

Draw now a line to indicate HOW SERIOUS you find this discrepancy: 